\title{
Mechanical Response of Borosilicate and Soda-Lime Glass Under Dynamic Triaxial Compression
}

\author{
John T. Chojnacki ${ }^{1}$ - Weinong W. Chen ${ }^{1}$
}

Received: 23 February 2016/Accepted: 24 March 2016/Published online: 4 April 2016

(C) Society for Experimental Mechanics, Inc 2016

\begin{abstract}
Dynamic triaxial compression experiments were performed on borosilicate and soda-lime glass using a triaxial compression Kolsky bar that has two pressure chambers, one enclosing the specimen and the other enclosing the end of the transmission bar. A specimen is pre-stressed hydrostatically before being loaded by a dynamic axial stress wave. Specimen axial stress and strain are determined at high strain rates under a range of hydrostatic pressures. Borosilicate glass was subjected to pressures of 25,50 , and $100 \mathrm{MPa}$ at a strain rate of $1500 \mathrm{~s}^{-1}$, and soda-lime glass was subjected to 25,50 , and $75 \mathrm{MPa}$ at $1100 \mathrm{~s}^{-1}$. Dynamic results were compared to high-rate unconfined experiments, as well as low-rate confined experiments. It was observed that confined glass strength did not show clear strain-rate dependency. But confining pressure increased the glass strength.
\end{abstract}

Keywords Kolsky bar (SHPB) - Triaxial · Glass · Borosilicate $\cdot$ Soda-lime

\section{Introduction}

Glass has been widely used in layered transparent vehicle armors where the glass material is subjected to high-rate, multiaxial compression loading. It is desired to determine the mechanical response of glass under such loading conditions. However, due to the limitations in experimental techniques, there have been a few studies on the high-rate

Weinong W. Chen

wchen@purdue.edu

1 Schools of Aero/Astro and Materials Engineering, Purdue University, West Lafayette, IN 47907, USA compressive response of glass under multiaxial compression. The method to simulate multiaxial compression was mainly through mechanical confining jackets. For example, $\mathrm{Xu}$ and Chen [1] studied the effects of loading rate, temperature, and damage effects on the compressive response of a borosilicate glass confined in sleeves of different materials. Chocron et al. [2-5] investigated the effects of damage on the strength of a borosilicate (Borofloat 33 manufactured by Schott Glass) and a soda-lime glass (Starphire manufactured by PPG) under confinement. They used thermo-shocks to create initial damage in the glass specimens and then subject the specimens to quasi-static triaxial loading. At high rates, the damaged cylindrical specimens are confined in metal jackets and subjected to axial compressive loading from a Kolsky bar.

Under quasi-static triaxial loading [6], the lateral surface of a cylindrical specimen is subjected to pressure boundary condition. At Kolsky bar rates, cylindrical surface is confined by a metallic cylindrical wall [7], resulting in a mixed pressure/elastic boundary condition. To identify the rate effects on the material response, it is necessary to unify the boundary conditions on the specimen. Since it is difficult to delineate the effects of confinement and friction at the specimen/wall interface in the metal sleeve configuration, it is desired to achieve dynamic triaxial loading conditions during the Kolsky bar experiments. For this purpose, a dynamic triaxial Kolsky bar has been developed [8, 9]. In this device, a compression experiment is performed in two stages. First, a pre-determined hydrostatic pressure is applied on the specimen in the testing section of a Kolsky bar, which is inside a pressure chamber. A dynamic axial stress wave loading is then applied to the specimen by the Kolsky bar. The method has been employed to explore the dynamic triaxial behavior of sand [10] and rock [11]. In this paper, this dynamic triaxial experimental setup is used 
to characterize the dynamic triaxial response of a borosilicate and soda-lime glass.

\section{Materials and Specimens}

The two glass materials experimented upon are a borosilicate glass named Borofloat 33 from Schott Inc. in Elmsford, NY, and a soda-lime glass named Starphire from PPG Industries in Pittsburgh, PA. The chemical composition and some physical and material properties are listed in Tables 1 and 2, respectively. Both borosilicate and sodalime glass materials are commonly used in layered transparent armors and thus have been the subject of investigations. Recent advances on the study of the mechanical behavior of these materials are summarized in a special journal issue $[12,13]$.

The glass supply came in the form of flat panels. The borosilicate panels had a thickness of $6.53 \mathrm{~mm}$ and the soda-lime panels $5.67 \mathrm{~mm}$. Cylindrical specimens were core-drilled out and then ground. The diameter of the cylindrical specimens for both materials was $4.75 \mathrm{~mm}$. The two flat ends of the each cylinder were the original flat surfaces of the panels, ensuring the parallelism of the loading surfaces. Specimens were inspected, weighed, and measured before each experiment to ensure consistency.

\section{Experimental Setup}

The experimental setup used in this study was a Kolsky bar integrated with a hydrostatic pressure system which enabled dynamic triaxial compression (DTXC) experiments [8, 9]. A schematic of the experimental setup is shown in Fig. 1 [8], and a photograph of the setup is shown in Fig. 2.

In this system, a specimen is placed between the incident and transmission bars, but is additionally sealed within a radial compression chamber. A second vessel, called the axial compression chamber, is connected to the same pressure line as the radial compression chamber and contains the end of the transmission bar in order to confine specimens axially. As a result, the axial compression chamber replaces the usual momentum bar and shock absorber. The fluid within the axial compression chamber restricts forward motion of the transmission bar during an experiment.
Table 2 Mechanical properties of Borofloat (borosilicate) and Starphire (soda-lime) glass [13]

\begin{tabular}{lllll}
\hline & $\rho\left(\mathrm{kg} \mathrm{cm}^{-3}\right)$ & $\mathrm{E}(\mathrm{GPa})$ & $v$ & $\sigma_{f s}(\mathrm{MPa})$ \\
\hline Borofloat 33 & 2200 & 64 & 0.20 & 25 \\
Starphire & 2510 & 73.1 & 0.22 & 41.4 \\
\hline
\end{tabular}

The pressure is controlled at a hydraulic pump by a computer according to predetermined profiles. Pressure from the hydraulic pump is amplified by a piston inside the intensifier, which pressurizes the axial and radial chambers simultaneously. A pressure transducer connected to the intensifier reports the pressure back to the computer for pressure profile control. The axial and radial chambers were proof tested at $500 \mathrm{MPa}$, and the intensifier was proof tested at $518 \mathrm{MPa}$. The hydraulic pump has a maximum working pressure of $13.8 \mathrm{MPa}$, and the intensifier, which amplifies the pressure from the hydraulic pump by a factor of 32, has a maximum working pressure of $440 \mathrm{MPa}$. The hydraulic pump pressurizes hydraulic oil; however, the output side of the intensifier uses an $80 \% / 20 \%$ mixture of kerosene and $10 \mathrm{~W}-30$ motor oil.

Pressurizing the axial and radial chambers compresses the incident and transmission bars in addition to the specimen, requiring the addition of the tie rods and restraining plate seen in Figs. 1 and 2. A hole through the restraining plate with a widened recess for a stopper on the incident bar side allows a compression stress wave to pass from the pre-incident bar though the stopper to the incident bar, without the incident bar sliding backward while confined. Having this pre-incident bar also facilitates easier alignment with the striker in the gas gun. Not pictured in Fig. 2 are platens, which are thin discs placed on each side of the specimen between the specimen-bar interfaces. Platens endure the scratches and dings from specimen failure that would otherwise damage the bar surfaces, and are easier to surface grind or replace.

The striker, pre-incident bar, incident bar, transmission bar, and platens all have a diameter of about $18.97 \mathrm{~mm}$, with lengths of $305,165,2103,1191$, and $3.05 \mathrm{~mm}$, respectively. The stopper has a diameter of $45.7 \mathrm{~mm}$ and a thickness of $25.4 \mathrm{~mm}$. The confining pressure was varied at 25, 50, and $100 \mathrm{MPa}$ for the borosilicate glass, and 25, 50, and $75 \mathrm{MPa}$ for the soda-lime glass. The experimental equipment is capable of achieving higher hydrostatic
Table 1 Percent composition of Borofloat (borosilicate) and Starphire (soda-lime) glass [13]

\begin{tabular}{lllllllllll}
\hline & $\mathrm{SiO}_{2}$ & $\mathrm{~B}_{2} \mathrm{O}_{3}$ & $\mathrm{Na}_{2} \mathrm{O}$ & $\mathrm{Al}_{2} \mathrm{O}_{3}$ & $\mathrm{~K}_{2} \mathrm{O}$ & $\mathrm{CaO}$ & $\mathrm{Fe}_{2} \mathrm{O}_{3}$ & $\mathrm{MgO}$ & $\mathrm{SrO}$ & $\mathrm{ZrO}_{2}$ \\
\hline Borofloat 33 & 80.54 & 12.7 & 3.54 & 2.54 & 0.64 & 0.02 & 0.015 & $<0.01$ & - & - \\
Starphire & 73.2 & - & 14.7 & 1.44 & 0.01 & 10.3 & 0.01 & 0.08 & 0.2 & 0.03 \\
\hline
\end{tabular}




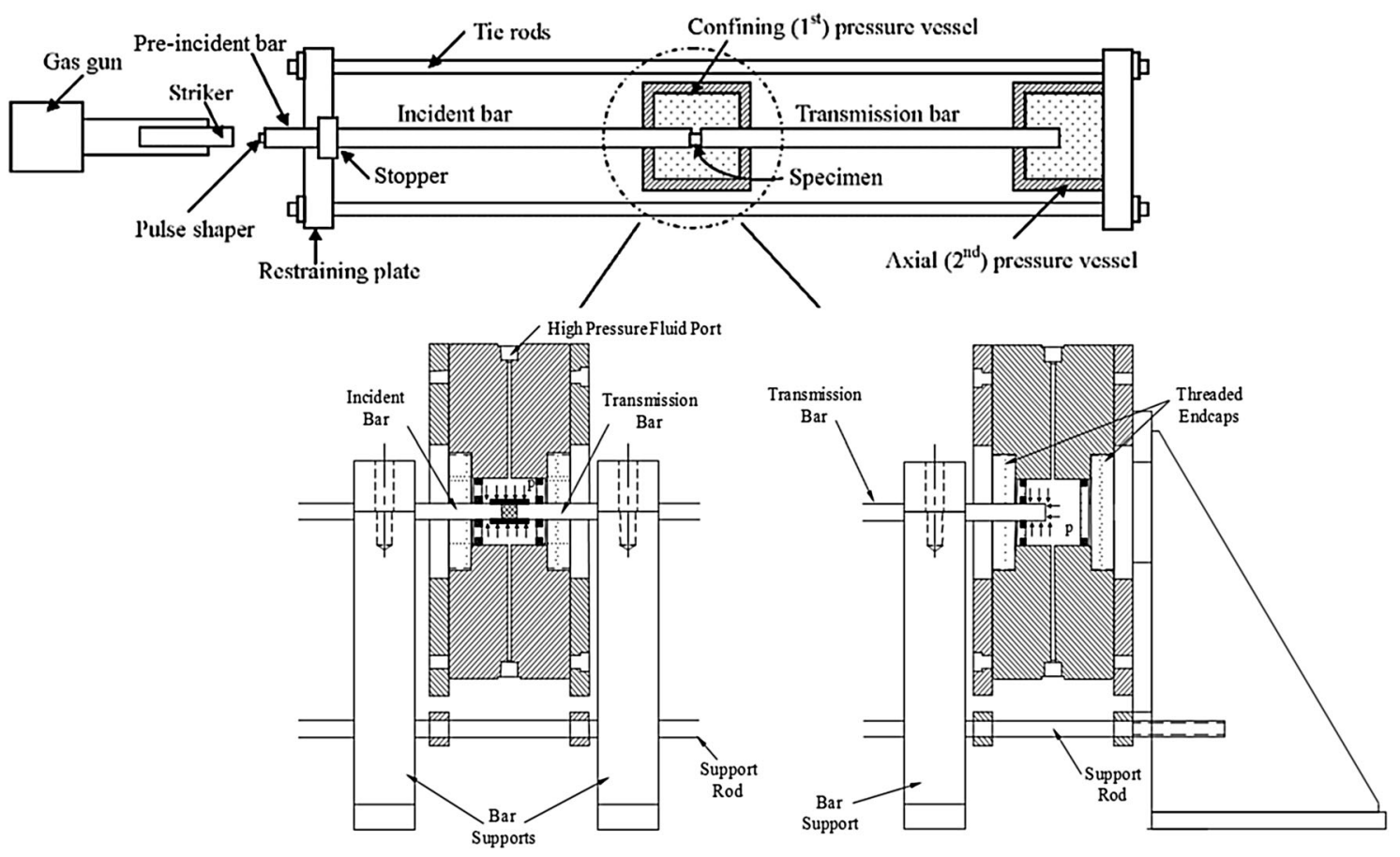

Fig. 1 A schematic of a triaxial compression Kolsky bar [8]

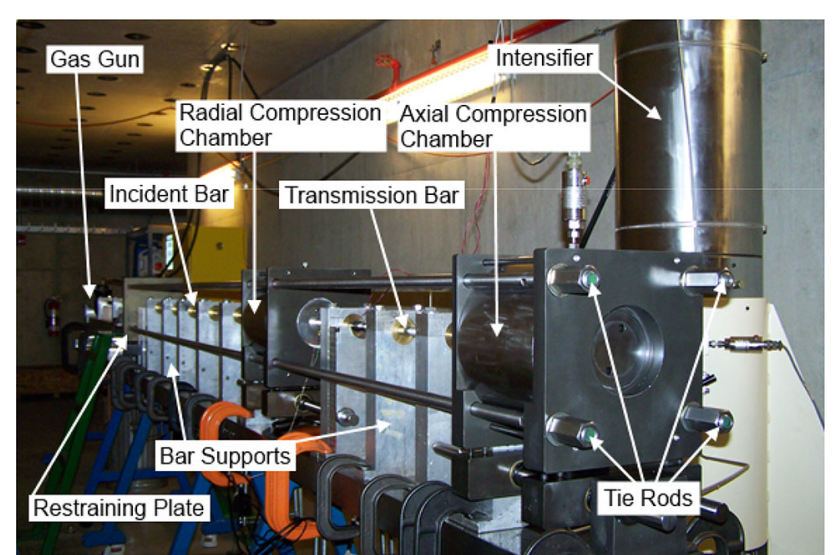

Fig. 2 Labeled image of the triaxial compression Kolsky bar

pressure (up to $400 \mathrm{MPa}$ ). However, under the axial impact conditions to achieve the consistent strain rate, the glass specimens did not fail under higher hydrostatic pressures. We report only the data when failure in the glass samples was observed under the confining pressures up to $100 \mathrm{MPa}$.

The experiments reported in this paper are performed in the strain-rate range that are typically achieved in a Kolsky bar set up $\left(\sim 10^{3} \mathrm{~s}^{-1}\right)$. To explore the mechanical response of glass under impact loading conditions, experiments at higher strain rates and higher pressure, such as those recently performed by Chocron et al. [14], are also desired to develop insights to the glass failure over a wider range of loading conditions.

\section{Experimental Procedure}

In the dynamic triaxial experiments, it is critically important to seal the specimen from the fluid around it. The majority of experiments performed on the triaxial compression Kolsky bar have been specimens with about the same diameter as the incident and transmission bars [10]. To seal these specimens, a piece of heat shrink tubing would be heated and shrunk to fit securely over the length of the specimen and platens. After this, the cut out neck of a balloon would be rolled over the heat shrink tubing, followed by an application of M-Coat B-1 nitrile rubber coating that required $2 \mathrm{~h}$ to dry before proceeding with an experiment. The heat shrink tubing, balloon neck, and nitrile rubber coating together provide sufficient protection for the specimen against the fluid that fills the radial confinement chamber, while also preventing fluid from getting in between the specimen-bar interface. A picture of a specimen prepared in this manner is shown in Fig. 3.

This sealing method presents a challenge for specimens much smaller than the bar, particularly the glass specimens, as these protective layers become ineffective at keeping fluid out of the bar-specimen interface. Proper sealing that separates the specimen from the pressure fluid is critical to obtain valid results from the experiments. If the fluid penetrates the seal, the fluid will get in between the specimen and bar interfaces, which changes the boundary conditions assumed on the specimen during the experiment. Also, the fluid will penetrate into the openings in the 


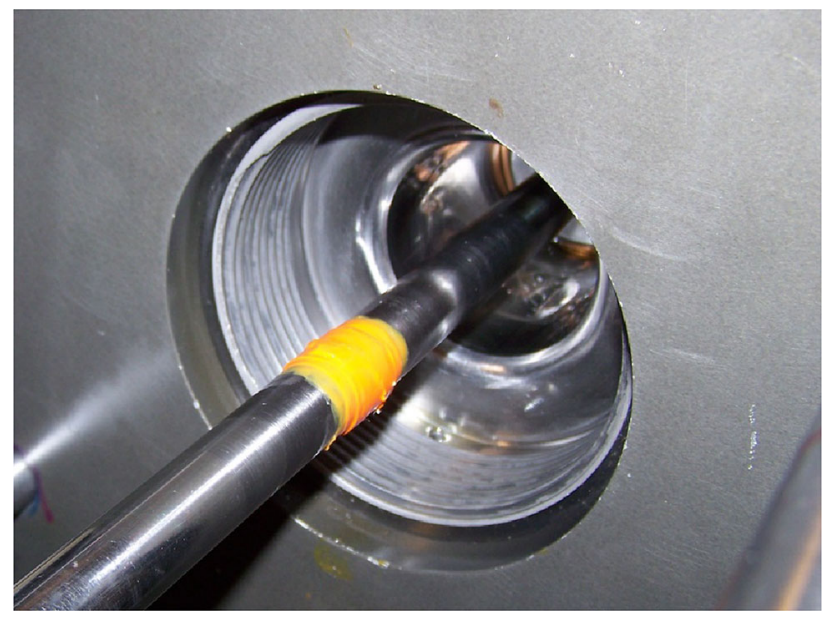

Fig. 3 A sealed acrylic specimen ready for an experiment

specimen created by the damage as the specimen is loaded up, changing the material response significantly through lubrication. Various attempts were made to remedy this situation. The solution eventually settled upon was to wrap the glass specimen in a heat shrink tube that was shrunk and cut to the length of the specimen. Then the specimen was placed between the platens. A seal around the specimen and platens was formed using J-B WaterWeld epoxy. The heat shrink tube was used to help the putty cling to the specimen, and the epoxy putty required an hour to cure after applying it. Figure 4 shows a glass specimen before and after the seal was applied. With the specimen sealed, the experiment proceeds by sliding the radial chamber forward so that the specimen is in the middle of the chamber, and screwing the door closed. Care is taken to not allow the incident bar to rotate during this operation, which would likely break the seal.

For the hydrostatic portion of the experiment, a linear variable differential transformer (LVDT) is attached to the incident and transmission bars just outside the radial chamber to measure the relative motion of the bars between these two points. The motion between these two attachment points subtracted by the elastic deformation of the bars inside the radial chamber gives the relative motion between the bar ends in contact with the specimen [10]. A datacollecting oscilloscope is set to collect data continuously. The axial and radial chambers are filled with the kerosene and motor oil mixture, air bubbles are bled from the top port of each chamber, and the ports are bolted closed. The confinement pressure is increased to the desired level for the experiment. At this point, a glance at the LVDT data will indicate whether axial confinement was successful or not. If the voltage change recorded from the LVDT shows expansion in the specimen rather than compression, then the seal has broken and fluid has leaked into the specimen-
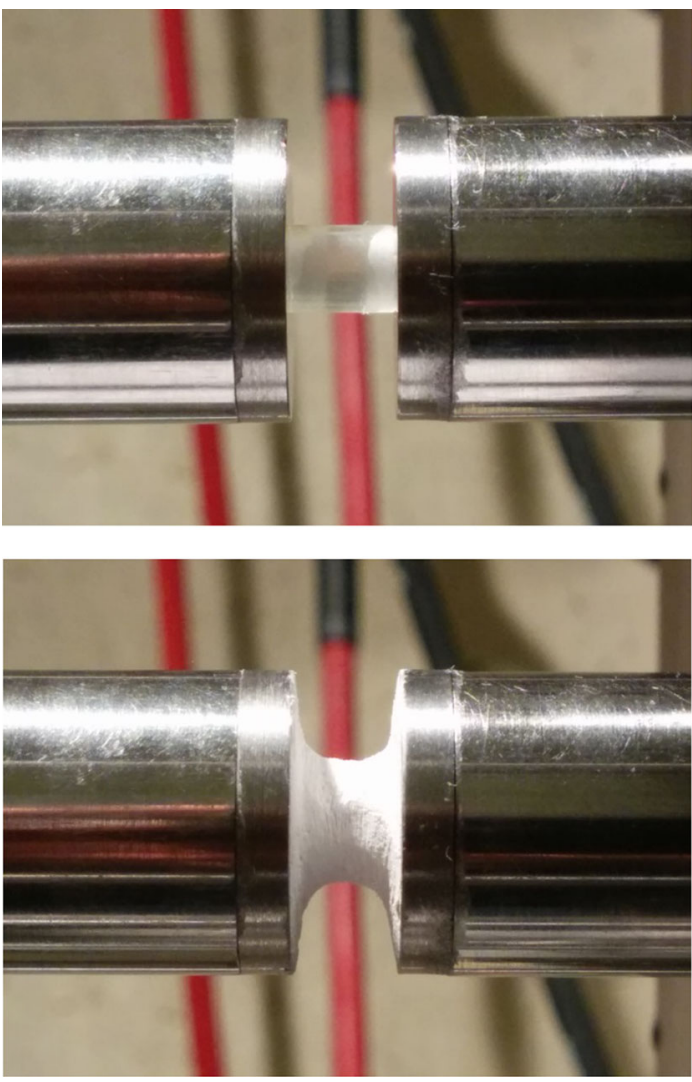

Fig. 4 Glass specimen before (top) and after (bottom) being sealed with WaterWeld

bar interface. Continuing the experiment from this point would not yield any useful results. If the seal appears to still be intact, then the pressure and LVDT data are recorded, the LVDT removed, and the experiment is ready to proceed to the dynamic portion.

For the dynamic portion of the experiment, the strain gages from the incident and transmission bars are reconnected and their signals zeroed. The oscilloscope is set to a single sequence trigger from the incident strain gage. The confinement pressure is verified and the gas gun is fired at the desired pressure in order to finally load the specimen at a high strain rate. Strain gage data from the oscilloscope is saved for later analysis. A half-hardened $\mathrm{Cu} 11017.5 \mathrm{~mm}$ in diameter, $0.5-\mathrm{mm}$ thick pulse shaper was placed on the front of the pre-incident bar with high pressure grease in the majority of the glass experiments reported in this paper. After the experiment is completed, the hydraulic pump is turned off, and any valves that were closed are reopened to relieve pressure. Fluid from the radial and axial chambers is drained into a waste container, the door to the radial chamber is opened, the remains of the specimen are saved if it is recoverable, and the area is cleaned in preparation for the next experiment. 
During an experiment, the confinement pressure, LVDT, and strain gage data are collected using a digital oscilloscope. Figure 5 shows an example of the data collected during an experiment on borosilicate with an initial 50-MPa hydrostatic confinement, after it is passed through a 9 point moving average filter and converted from voltage into the appropriate units. Note that the upper two graphs correspond to the hydrostatic phase where the specimen is slowly pressured; the bottom graph corresponds to the dynamic phase where the striker creates a compressive wave to break the specimen. The incident, reflected and transmitted waves are used to verify that the specimen is in dynamic equilibrium during the dynamic phase of the experiment using a one-wave, two-wave method [15].

Figure 6 shows the strain rate history and stress versus strain graphs obtained from the experiment on borosilicate. During the experiment, the strain rate ramps up and levels out at a somewhat constant level of $1500 \mathrm{~s}^{-1}$ before rapidly increasing to indicate failure in the specimen. The principal stress difference increases to about $3000 \mathrm{MPa}$ before the specimen completely fails. Note that this stress value does not account for the initial $50 \mathrm{MPa}$ of axial and radial confinement applied to the specimen. After the unstable region at the specimen failure on the stress-strain curve in Fig. 6, the specimen resume some capacity of resisting axial load at a level of slightly below $1000 \mathrm{MPa}$ as the axial strain further increases. This is the result of the broken specimen being contained inside the sealed enclosure.
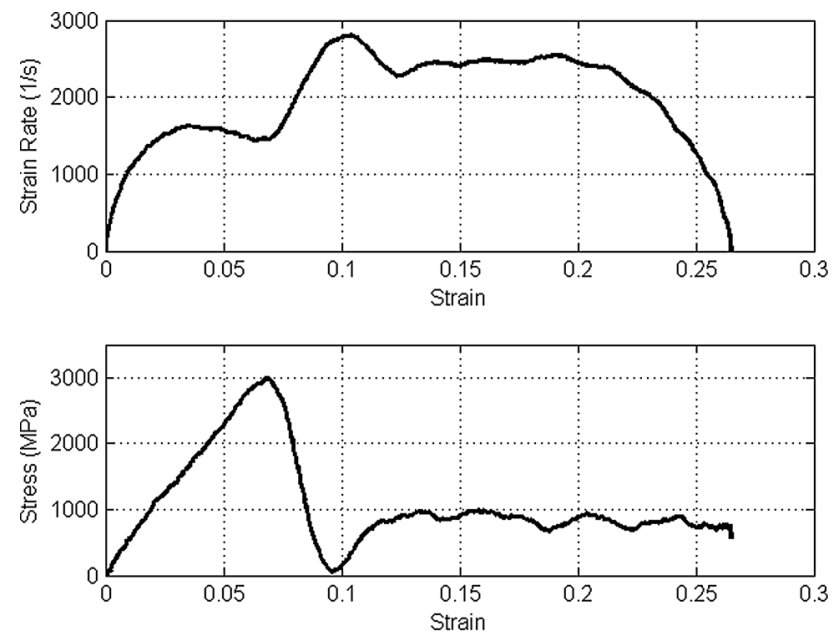

Fig. 6 Strain rate history (top) and stress-strain curve (bottom) for borosilicate glass

\section{Experimental Results}

\section{Borosilicate Glass}

Table 3 summarizes the confinement pressure $P_{\mathrm{c}}$, impact velocity of the striker $\mathrm{v}_{\mathrm{s}}$, pulse shaper used, average dynamic stain rate $\dot{\varepsilon}$, and principal stress difference at failure $\sigma_{e q}$, for experiments conducted on the borosilicate glass. Figure 7 shows the dependence of $\sigma_{e q}$ on the confining pressure $P_{\mathrm{c}}$.
Fig. 5 Smoothed and converted data for confinement pressure (top left), LVDT (top right), and strain gages (bottom)
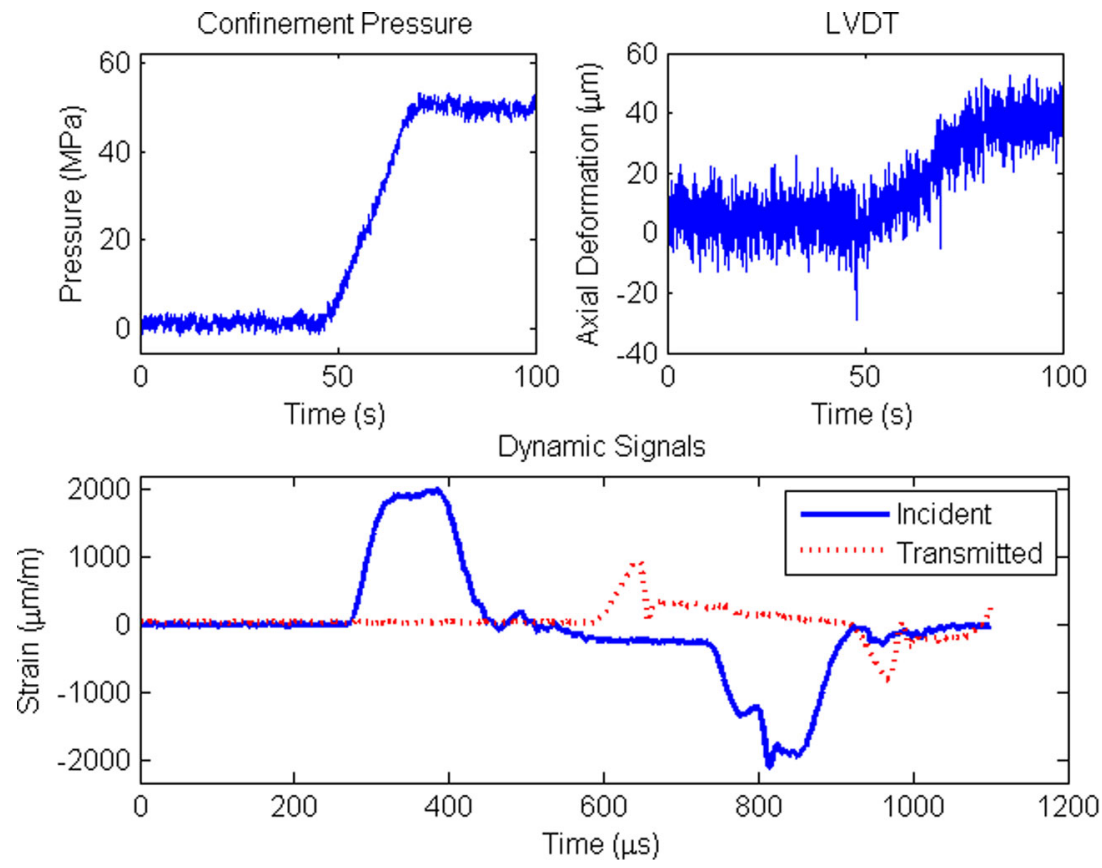
Table 3 Summary of experiments conducted on borosilicate glass

\begin{tabular}{|c|c|c|c|c|c|}
\hline Sample \# & $\mathrm{P}_{\mathrm{c}}(\mathrm{MPa})$ & $\mathrm{V}_{\mathrm{s}}\left(\mathrm{m} \mathrm{s}^{-1}\right)$ & Pulse shaper (in) & $\dot{\varepsilon}\left(\mathrm{s}^{-1}\right)$ & $\sigma_{e q}(\mathrm{MPa})$ \\
\hline 44 & - & - & - & 0.001 & 1889 \\
\hline 45 & - & - & - & 0.001 & 1571 \\
\hline 46 & - & - & - & 0.001 & 1592 \\
\hline 34 & - & 21 & $\mathrm{Cu} 110(11 / 16,0.02)$ & $\sim 1800$ & 1903 \\
\hline 35 & - & 17 & $\mathrm{Cu} 110(11 / 16,0.02)$ & $\sim 1400$ & 2004 \\
\hline 36 & - & 15 & $\mathrm{Cu} 110(11 / 16,0.02)$ & $\sim 1300$ & 1813 \\
\hline 37 & - & 14 & $\mathrm{Cu} 110(11 / 16,0.02)$ & $\sim 1200$ & 1924 \\
\hline 39 & - & 15 & $\mathrm{Cu} 110(11 / 16,0.02)$ & $\sim 1300$ & 1962 \\
\hline 24 & 25 & 21 & $\mathrm{Cu} 110(11 / 16,0.02)$ & $\sim 1650$ & 2862 \\
\hline 25 & 25 & 21 & $\mathrm{Cu} 110(11 / 16,0.02)$ & $\sim 1650$ & 2989 \\
\hline 26 & 25 & 21 & $\mathrm{Cu} 110(11 / 16,0.02)$ & $\sim 1600$ & 3069 \\
\hline 40 & 25 & 21 & $\mathrm{Cu} 110(11 / 16,0.02)$ & $\sim 1600$ & 3072 \\
\hline 21 & 50 & 21 & $\mathrm{Cu} 110(11 / 16,0.02)$ & $\sim 1500$ & 2883 \\
\hline 27 & 50 & 21 & $\mathrm{Cu} 110(11 / 16,0.02)$ & $\sim 1550$ & 2779 \\
\hline 33 & 50 & 21 & $\mathrm{Cu} 110(11 / 16,0.02)$ & $\sim 1500$ & 3001 \\
\hline 42 & 50 & 21 & $\mathrm{Cu} 110(11 / 16,0.02)$ & $\sim 1500$ & 3005 \\
\hline 28 & 100 & 21 & $\mathrm{Cu} 110(11 / 16,0.02)$ & $\sim 1450$ & 2789 \\
\hline 29 & 100 & 21 & $\mathrm{Cu} 110(11 / 16,0.02)$ & $\sim 1400$ & 2965 \\
\hline 31 & 100 & 21 & $\mathrm{Cu} 110(11 / 16,0.02)$ & $\sim 1400$ & 2784 \\
\hline 43 & 100 & 21 & $\mathrm{Cu} 110(11 / 16,0.02)$ & $\sim 1350$ & 2954 \\
\hline
\end{tabular}

The results along the vertical axis (zero confining pressure) in Fig. 7 indicate that the unconfined compression experiments at both quasi-static and dynamic rates do not show significant rate effects on the compressive strength. However, there is a notable increase in strength from unconfined to confined experiments, but there is a negligible change in strength over the range of confinement pressures achieved in the experiments conducted in this research.

\section{Soda-Lime Glass}

Similar to Table 3, Table 4 summarizes the confinement pressure $P_{\mathrm{c}}$, impact velocity of the striker $\mathrm{v}_{\mathrm{s}}$, pulse shaper used, average stain rate $\dot{\varepsilon}$, and principal stress difference at

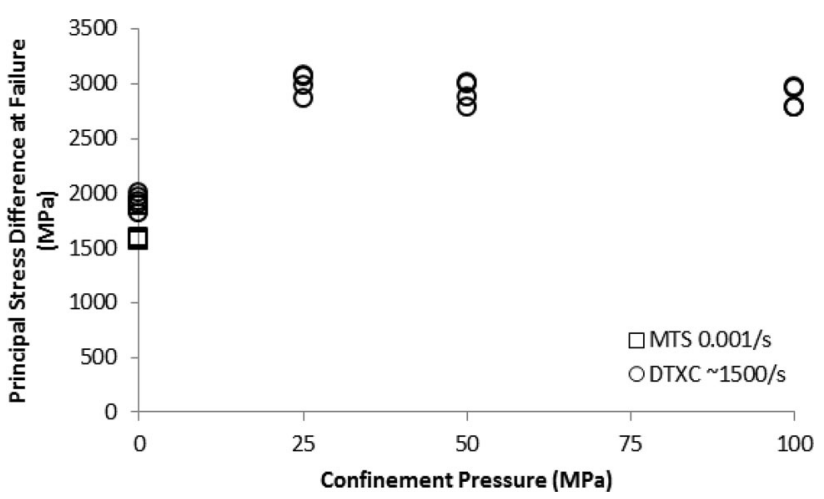

Fig. 7 Variation of principal stress difference at failure as a function of confinement pressure for borosilicate glass failure $\sigma_{e q}$, for experiments conducted on the soda-lime glass. It is noticed that the striking conditions are different from those listed in Table 3. This is the result of the attempts to achieve similar constant strain rates where the striking velocities and pulse shapers are adjusted. Figure 8 shows the variation of $\sigma_{e q}$ as a function of $P_{\mathrm{c}}$.

A comparison of the results presented in Figs. 7 and 8 indicates that the soda-lime glass has an overall lower strength than borosilicate glass, but the dependence of strength on pressure shares similar trends. There appears to be no significant rate dependence on strength from the unconfined experiments. There is a notable jump in strength from unconfined to confined experiments, but there is a negligible change in strength over the range of confinement pressures observed.

To compare these experimental results with the quasistatic results in literature, we replotted the borosilicate and soda-lime glass results by Chocron et al. [3, 4], in Figs. 9 and 10 , respectively, which are in the form of equivalent stress versus hydrostatic pressure. As a baseline check, we also performed unconfined quasi-static experiments using an MTS. To include the dynamic experimental results reported in Figs. 7 and 8, hydrostatic pressure can be rewritten as $P=P_{c}+\frac{1}{3} \sigma_{e q}$, where $P_{c}$ is the fluid confinement pressure applied axially and radially, and $\sigma_{e q}$ is the principal stress difference at failure. Figure 9 shows $\sigma_{e q}$ as a function of $P$ for dynamic compression, dynamic triaxial compression, and quasi-static MTS experiments in comparison to Chocron et al. [3] for borosilicate glass. The 
Table 4 Summary of experiments conducted on sodalime glass

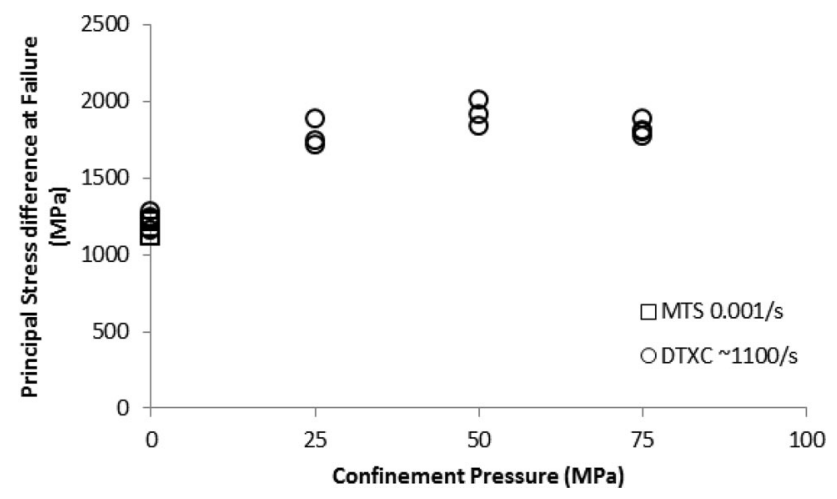

Fig. 8 Variation of principal stress difference at failure with confinement pressure for the soda-lime glass

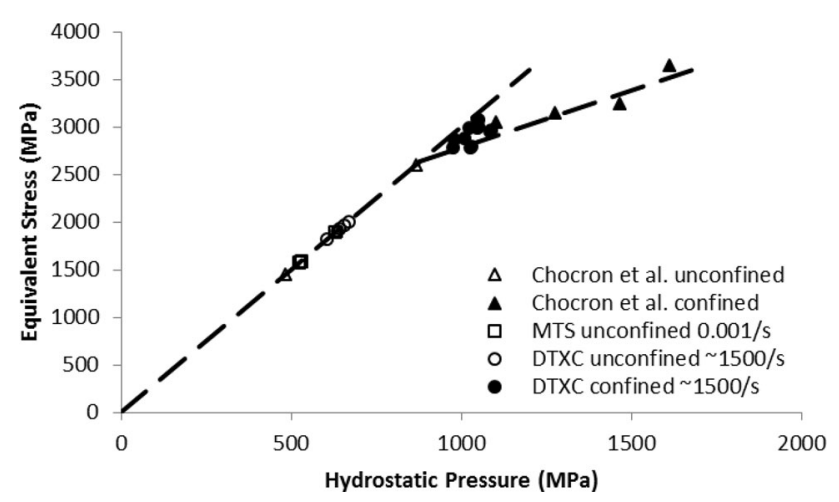

Fig. 9 Comparison of borosilicate specimens tested under triaxial compression, dynamic triaxial compression, and with an MTS [3]

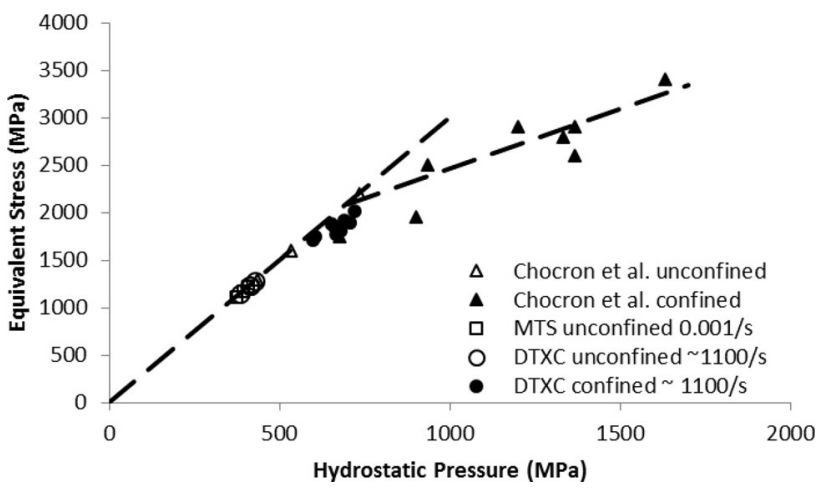

Fig. 10 Comparison of soda-lime specimens tested under triaxial compression, dynamic triaxial compression, and with an MTS [4]

results show that dynamic triaxial compression experiments conducted in this research yield results that agree well with the published results obtained quasi-statically. The quasi-static MTS results also fall on the same curve. These facts clearly indicate that the borosilicate glass is not sensitive to strain rate, especially under the confinement achieved in the reported experiments.

Similarly, Fig. 10 shows the variation of $\sigma_{e q}$ as a function of $P$ from dynamic compression, dynamic triaxial compression, and MTS experiments in comparison to Chocron et al. [4] for the soda-lime glass. As shown in Fig. 10, the observations made about borosilicate glass also apply to the soda-lime glass, although the average failure strength obtained by the DTXC method for the soda-lime 
glass was slightly lower than the trend reported in literature.

The experimental results presented in this paper were obtained at the typical Kolsky bar strain-rate range $\left(\sim 10^{3} \mathrm{~s}^{-1}\right)$. Experimental results at higher strain rates are still very limited, e,g., Chocron et al. [14], to compare the results over a very wide range of strain rates. However, there have been more studies on the rate and confinement effects on brittle materials such as ceramics. For example, Lankford et al. [16] argued that, as the strain rate is increased from quasi-static to plate-impact $\left(>10^{5} \mathrm{~s}^{-1}\right)$, the compressive strength of the brittle specimen material should increase gradually with increasing strain rate over the quasi-static rates, and then increase rapidly with rates over the Kolsky-bar rate range. As the rate is further increased, the "uniaxial stress" compressive strength should eventually coincide with the compressive strength obtained from plate-impact experiments under uniaxial strain conditions.

\section{Conclusions}

Compression experiments were performed on a borosilicate and a soda-lime glass at a quasi-static strain rate $\left(0.001 \mathrm{~s}^{-1}\right)$ using an MTS, and at a high strain rate ( $\sim 1500 \mathrm{~s}^{-1}$ for borosilicate, $\sim 1100 \mathrm{~s}^{-1}$ for soda-lime) using a modified triaxial compression Kolsky bar. Experiments on the Kolsky bar were performed unconfined and triaxially confined to 25,50 , and $100 \mathrm{MPa}$ for borosilicate glass, and 25, 50, and $75 \mathrm{MPa}$ for soda-lime glass. The dynamic strength of both glass materials increased significantly from unconfined to confined experiments. However, the strength did not further increase with increasing confining pressures achieved in this research. The results of the dynamic triaxial compression experiments performed in this study agree well with the quasi-static triaxial compression results found in literature, indicating minimum strain rate effects for the two glass materials under triaxial loading conditions.

Acknowledgments The corresponding author's time writing this article was partially sponsored by the Office of Naval Research through the Grant N00014-14-1-0628.

\section{References}

1. Nie X, Chen W (2013) High-rate progressive failure of borosilicate glass under mechanical confinement at high temperatures. Exp Mech 53:67-75

2. Chocron S, Dannemann K, Walker J, Nicholls A, Anderson C (2007) Constitutive model for damaged borosilicate glass under confinement. J Am Ceram Soc 90(8):2549-2555

3. Chocron S, Anderson C, Nicholls A, Dannemann K (2010) Characterization of confined intact and damaged borosilicate glass. J Am Ceram Soc 93(10):3390-3398

4. Chocron S, Anderson C, Dannemann E, Nicholls K (2013) Pressure effects on the compressive response of confined intact and damaged soda-lime glass. Exp Mech 53(1):77-89

5. Dannemann K, Anderson C, Chocron S, Spencer J (2012) Damage development in confined borosilicate and soda-lime glasses. J Am Ceram Soc 95(2):721-729

6. Akers SA, Reed PA, Ehrgott JQ (1986) WES high-pressure uniaxial strain and triaxial shear test equipment. Miscellaneous Paper SL-86-11, U.S. Army Engineers, Waterways Experiment Station, Vicksburg, MS

7. Bhushan B, Jahsman WE (1978) Measurement of dynamic material behavior under nearly uniaxial strain conditions. Int $\mathbf{J}$ Solids Struct 14:739-753

8. Frew D, Akers S, Chen W, Green M (2010) Developmentof a dynamic triaxial kolsky bar. Meas Sci Technol 21:105704

9. Kabir M, Chen W (2009) Measurement of specimen dimensions and dynamic pressure in dynamic triaxial experiments. Rev Sci Instrum 80(12):125111

10. Martin B, Kabir ME, Chen W (2013) Undrained high-pressure and high strain-rate response of dry sand under triaxial loading. Int J Impact Eng 54:51-63

11. Hokka M, Black J, Tkalich D, Fourmeau M, Kane A, Hoang N-H, Li CC, Chen WW, Kuokkala V-T (2016) Effects of strain rate and confining pressure on the compressive behavior of kuru granite. Int J Impact Eng 91:183-193

12. Talladay TG, Templeton DW (2014) Glass armor-an overview. Int J Appl Glass Sci 5(4):331-333

13. Parab ND, Black JT, Claus B, Hudspeth M, Sun J, Fezzaa K, Chen W (2014) Observation of crack propagation in glass using X-ray phase contrast imaging. Int J Appl Glass Sci 5(4):363-373

14. Chocron S, Barnette DD, Holmquist TJ, Anderson CE, Bigger RP, Moore TZ (2016) Damage threshold of borosilicate glass under plate impact. J Dyn Behav Mater. doi:10.1007/s40870-0160056-4

15. Chen W, Song B (2011) Split Hopkinson (Kolsky) bar design, testing and applications (Mechanical engineering series). Springer, New York

16. Lankford J, Anderson CE, Nagy AJ, Walker JD, Nicholas AE, Page RA (1998) Inelastic response of confined aluminum oxide under dynamic loading conditions. J Mater Sci 33:1619-1625 